Revue Française de Civilisation Britannique

\title{
Hommage à Jacques Leruez
}

Farewell to Jacques Leruez

Jean-Didier Hache

\section{(2) OpenEdition}

1 Journals

Édition électronique

URL : http://journals.openedition.org/rfcb/4788

DOI : $10.4000 / \mathrm{rfcb} .4788$

ISSN : 2429-4373

Éditeur

CRECIB - Centre de recherche et d'études en civilisation britannique

Référence électronique

Jean-Didier Hache, «Hommage à Jacques Leruez », Revue Française de Civilisation Britannique [En ligne], XXIV-4 | 2019, mis en ligne le 25 novembre 2019, consulté le 27 novembre 2019. URL : http:// journals.openedition.org/rfcb/4788; DOI : 10.4000/rfcb.4788

Ce document a été généré automatiquement le 27 novembre 2019.

\section{(c) $(1)$}

Revue française de civilisation britannique est mis à disposition selon les termes de la licence Creative Commons Attribution - Pas d'Utilisation Commerciale - Pas de Modification 4.0 International. 


\title{
Hommage à Jacques Leruez
}

\author{
Farewell to Jacques Leruez
}

\section{Jean-Didier Hache}

1 Le géographe André Siegfried, citant Michelet, se plaisait à dire à ses élèves: «L'Angleterre est une île, maintenant vous en savez autant que moi ... ».

Mais ceci était avant Jacques Leruez.

Non seulement ce dernier nous a-t-il permis, à travers une riche collection de publications majeures sur les institutions et la vie politique britanniques, d'en comprendre les mystères - et ce au-delà d'un simple effet de l'insularité -, mais surtout nous a-t-il rappelé que le Royaume-Uni ne se limitait pas à la seule Angleterre...chose que de trop nombreux Français ignoraient, et ignorent hélas parfois encore !

À l'heure où le Royaume-Uni poursuit une navigation aussi tumultueuse qu'incertaine dans les méandres du Brexit (navigation dont, à l'heure ou ces lignes sont écrites, on ne saurait prédire l'issue), c'est à cet aspect son œuvre qu'il nous faut tout particulièrement songer.

Car la question du «Brexit » est, à plusieurs titres, hantée par la nature des rapports au sein des diverses entités qui composent les îles britanniques, domaine auquel Leruez avait consacré une majeure partie de ses travaux.

Fantôme le plus évident, celui du rétablissement d'une frontière physique entre l'Irlande du Nord et la République d'Irlande, laquelle violerait les termes du « Good Friday agreement" et pourrait raviver les troubles d'Ulster. Situation paradoxale d'ailleurs, qui a vu la survie du gouvernement de Mme May - et le blocage subséquent de l'accord sur le Brexit - tenir à l'appui d'une petite formation unioniste particulièrement intransigeante à tout compromis; ce alors que l'électorat de l'Irlande du Nord a, dans sa majorité, voté en faveur du « remain »!

Nul doute que l'amusement de Collins, Griffth ou De Valera serait grand s'ils pouvaient voir la partition de l'Irlande, contre laquelle ils s'étaient battus les armes à la main dans les années 1920, mettre l'ancienne puissance coloniale dans une situation aussi inextricable près d'un siècle plus tard...

Autre fantôme irlandais, plus lointain encore, que celui des récents efforts de la Chambre des Communes pour s'emparer du gouvernail des négociations du Brexit, en 
remettant en cause la préséance de l'Exécutif dans la fixation de l'ordre du jour parlementaire. Rappelons en effet que cette préséance remonte aux mesures mises en œuvre dans les années 1880 pour contrecarrer les techniques «d'obstruction parlementaire » déployées par Parnell afin de soulever la question irlandaise. Parnell, lui aussi, rirait probablement beaucoup de voir le Speaker de la Chambre, John Bercow, contraint de remettre en question cette «tradition parlementaire » qui fut créée à son encontre il y a près de 140 ans.

Fantôme écossais, enfin, avec une Écosse qui ayant voté aux deux tiers pour rester dans l'Union Européenne, se voit entraînée contre son gré dans le "Brexit ». Paradoxe là encore, puisque c'est la perspective d'une sortie automatique de l'Écosse de l'UE en cas de majorité de «oui » lors du référendum sur l'indépendance de 2014, qui avait été l'une des menaces majeures brandie par les partisans du «non ». Or, c'est précisément la victoire du statu quo lors dudit referendum qui va obliger les Écossais à sortir de l'UE avec l'ensemble du Royaume-Uni.

Et c'est aussi, en partie du moins, la crainte de devoir céder demain à la demande d'un second référendum sur l'indépendance écossaise qui expliquait la réticence de Mme May, comme celle du Leader de l'opposition M. Jeremy Corbyn, à proposer un second référendum sur la question du «Brexit».

Jacques Leruez l'avait bien compris: on ne saurait apprécier pleinement la politique britannique sans prendre en compte l'histoire complexe des rapports entre l'Angleterre et ses nations voisines.

Lors de la montée du nationalisme écossais, et des divers référendums qui s'en suivirent, Jacques Leruez et moi avions passé de longues (parfois trop longues!) heures au téléphone pour discuter de la situation écossaise.

Nul doute que les aventures du Brexit eussent à nouveau mis les réseaux téléphoniques en péril. Hélas, le téléphone ne sonnera plus...

\section{AUTEUR}

\section{JEAN-DIDIER HACHE}

Retraité, partage sa vie entre la France et l'Écosse 